\title{
Bioinspired negatively charged calcium phosphate nanocarriers for cardiac delivery of MicroRNAs
}

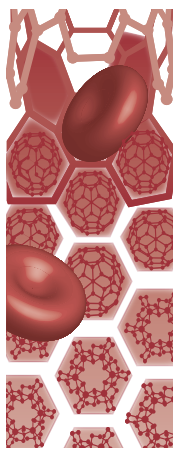

\begin{abstract}
Aim: To develop biocompatible and bioresorbable negatively charged calcium phosphate nanoparticles (CaP-NPs) as an innovative therapeutic system for the delivery of bioactive molecules to the heart. Materials \& methods: CaP-NPs were synthesized via a straightforward one-pot biomineralization-inspired protocol employing citrate as a stabilizing agent and regulator of crystal growth. CaP-NPs were administered to cardiac cells in vitro and effects of treatments were assessed. CaP-NPs were administered in vivo and delivery of microRNAs was evaluated. Results: CaP-NPs efficiently internalized into cardiomyocytes without promoting toxicity or interfering with any functional properties. CaP-NPs successfully encapsulated synthetic microRNAs, which were efficiently delivered into cardiac cells in vitro and in vivo. Conclusion: CaP-NPs are a safe and efficient drug-delivery system for potential therapeutic treatments of polarized cells such as cardiomyocytes.
\end{abstract}

First draft submitted: 18 August 2015; Accepted for publication: 3 February 2016; Published online: 16 March 2016

Keywords: calcium phosphate nanoparticles $\bullet$ cardiomyocytes $\bullet$ drug-delivery systems - microRNA • nanomedicine

Cardiovascular disease (CVD) is a worldwide growing problem that afflicts close to $1 \%$ of the population and causes 17.3 million annual premature deaths [1]. Causes include ischemic, toxic, genetic, postinflammatory and structural defects, overall resulting in a mortality of $\sim 50 \%$ within 5 years from diagnosis [2]. Clinical management of CVDs has improved during the last decades, but despite significant advancements, these pathologies still lead to a poor quality of life and reduced longevity. Moreover, the prognosis has been described as more malignant than cancer. Altogether, this entails the critical need to further understand the mechanisms underlying CVDs, to identify innovative therapeutic compounds as well as to develop more efficient and safe drug-delivery systems. MicroRNAs (miRNAs; miRs) are small regulatory RNA molecules shown to be disease-specific biomarkers and key regu- lators of cardiac dysfunction [3,4]. In line with this, significant effort has been put into developing new therapeutic tools designated to correct levels of miRNAs found to be dysregulated in CVDs [5]. Modified antisense oligonucleotides such as 2-O-methyl-modified ones, antagomirs and locked nucleic acids have been largely applied for therapeutic knockdown of miRNA levels both in in vitro and in vivo models of CVDs [3]. On the other hand, approaches aimed at increasing the in vivo levels of miRNAs are still not optimal and require drastic improvements and new solutions. In fact, current miRNA mimics in terms of in vivo delivery, stabilization, efficacy of overexpression and cell targeting have resulted so far to be inadequate, with use of miRNA-expressing adeno-associated viruses $(\mathrm{AAV})$ as the only alternative strategy $[6,7]$. However, the long-term miRNA expression associated with AAV technology drastically
Vittoria Di Mauro $\$, 1,2$, Michele Iafisco ${ }^{\ddagger, 3}$, Nicolò Salvarani ${ }^{1}, 2$, Marco Vacchiano', Pierluigi Carullo, ${ }^{1,2}$, Gloria Belén Ramírez-Rodríguez ${ }^{3}$, Tatiana Patrício ${ }^{3}$, Anna Tampieri ${ }^{3}$, Michele Miragoli $*, 1,2$ \& Daniele Catalucci**,1,2

${ }^{1}$ National Research Council (CNR), Institute of Genetics \& Biomedical Research, Milan Unit, Milan 20138, Italy ${ }^{2}$ Humanitas Clinical \& Research Center, Rozzano (MI) 20089, Italy ${ }^{3}$ National Research Council (CNR), Institute of Science \& Technology for Ceramics (ISTEC) 48018 Faenza (RA) Italy

*Author for correspondence: michele.miragoli@humanitasresearch.it **Author for correspondence: daniele.catalucci@cnr.it

${ }^{\ddagger}$ Authors contributed equally 
limits any therapeutic approach that requires shortterm and/or interval drug administration.

Nanoparticle (NP) delivery platforms hold great promise to overcome such limitations, providing an alternative strategy for more efficient, controlled and safe drug-delivery approaches. In fact, NPs potentially bind and deliver a large plethora of agents such as conventional drugs and more recently, nucleotides [8-10]. Additionally, NPs can offer a substantial protection of the payload against immediate diffusion from or degradation in the bloodstream and at the injury site, thus enabling controlled drug release and sustained therapeutic stimulus [10]. However, while largely investigated in the cancer field, the development and use of efficient NPs for the treatment of CVDs is still in its infancy. In fact, to the best of our knowledge, only liposomes, NPs based on synthetic polymers or silica and micelles have been investigated so far for the delivery of various therapeutic molecules to myocardial cells [11-15]. However, in many cases, their use is drastically limited due to the lack of biocompatibility, reduced or very slow biodegradability [16], uncontrolled drug release in the bloodstream, poor encapsulation efficacy and poor stability during storage [17]. Additionally, optimization of the synthesis of cardiac-compatible NPs requires improved colloidal stability, and specific size, shape and surface charge [18]. In line with this, we recently demonstrated that polystyrene latex NPs are less toxic for cardiac cells when generated with a negative surface charge, which is compatible with the intrinsic charge of well-polarized excitable cells (i.e., cardiomyocytes) and facilitates the formation of life-compatible nanopores and cellular internalization of NPs [19]. However, the slow dissolution and cell accumulation of polystyrene latex restricts the use of these NPs for therapeutic approaches. In summary, there is still a strong need for the identification of new formulations based on biocompatible and biodegradable negatively charged NPs to overcome the limitations of NPs currently used for CVD treatment.

The aim of the present study was the generation of innovative and effective negatively charged calcium phosphate nanoparticles (CaP-NPs) for the delivery of novel therapeutic drugs (i.e., miRNAs) into cardiac tissue. To this end, a simple and straightforward onepot mineralization synthesis protocol using citrate as stabilizing agent has been adopted. The biocompatibility and the mechanism of internalization of CaP-NPs in cardiac cells were obtained and the proof of concept for the ability of CaP-NPs to deliver miRNAs in vivo into cardiac tissue was provided.

\section{Material \& methods}

Synthesis of calcium phosphate nanoparticles

Functional CaP-NPs were generated according to a quick and simple protocol. Briefly, two aqueous solutions of $\mathrm{CaCl}_{2}(10-50 \mathrm{mM})+\mathrm{Na}_{3}$ Cit $(40-200 \mathrm{mM})$ and $\mathrm{Na}_{2} \mathrm{HPO}_{4}(12-60 \mathrm{mM})$ were mixed $(1: 1 \mathrm{v} / \mathrm{v}, 5 \mathrm{ml}$ total) and the $\mathrm{pH}$ was adjusted to 8.5 , adding $\mathrm{NaOH}$ aqueous solution. The mixed solution was kept in a water bath at $37^{\circ} \mathrm{C}$ for different times ranging from 5 to $60 \mathrm{~min}$. When drug conjugation was performed, aqueous solution of synthetic unmodified and unprotected miRNA duplexes (1-10 $\mu \mathrm{g} / \mathrm{ml}$, IBA, Germany) was added to the above mixed solution. To remove unreacted reagents, the CaP-NP suspension was washed three-times by centrifugation or dialyzed for $6 \mathrm{~h}$ across a cellulose dialysis membrane with a cut-off of $3500 \mathrm{Da}$ and immersed in $400 \mathrm{ml}$ Milli-Q water. The suspension was recovered and stored in a fridge at $4^{\circ} \mathrm{C}$. The amount of $\mathrm{CaP}$ was evaluated by freeze-drying the sample suspensions and weighting the inorganic residual. The final concentration of aqueous $\mathrm{CaP}$ suspension ranged from 60 to $300 \mu \mathrm{g} / \mathrm{ml}$ as a function of reagent concentration.

\section{Characterization of CaP-NPs \& CaP-NP-miRs}

Size distribution and surface charge of CaP-NPs were evaluated by dynamic light scattering (DLS) and $\zeta$-potential, respectively. CaP-NP suspensions were characterized without any dilution by DLS using a Zetasizer Nano Series (Malvern, UK) by backscatter detection $\left(\lambda=630 \mathrm{~nm}, \theta=173^{\circ}\right)$. Particle size (reported as $Z$-average of hydrodynamic diameter) was calculated as the average of three measurements of 10 runs for $10 \mathrm{~s}$ at $37^{\circ} \mathrm{C}$. $\zeta$-potential measurements through electrophoretic mobility were carried out with a Zetasizer Nano analyzer (Malvern, UK) using disposable folded capillary cells (DTS1061; Malvern, UK) at $25^{\circ} \mathrm{C}$, suspending CaP-NPs in $10 \mathrm{mM}$ HEPES buffer at $\mathrm{pH}$ 7.4. Three separate measurements (100 runs each) were collected in each case. Size and photon counts were also recorded continuously up to $300 \mathrm{~min}$ to evaluate the colloidal stability of CaP-NPs. Infrared spectra of freeze-dried samples were collected using a Nicolect 380 spectrometer (Thermo Fisher Scientific, USA) with a resolution of $2 \mathrm{~cm}^{-1} .1 \mathrm{mg}$ of sample was mixed with $150 \mathrm{mg}$ of anhydrous potassium bromide $(\mathrm{KBr})$. The mixture was pressed at $10 \mathrm{~T}$ pressure into a $7 \mathrm{~mm}$ diameter disc. A pure $\mathrm{KBr}$ disk was used as blank. Transmission electron microscopy (TEM) images and energy dispersive x-ray spectrum were collected using an FEI Tecnai F20 ST microscope operating at $200 \mathrm{kV}$. An aliquot of $20 \mu \mathrm{l}$ of CaP-NP suspension was placed on carbon/formvar coated-copper grid for $5 \mathrm{~min}$. The grid was then washed with ultrapure water and dried by manual blotting.

\section{Cell line \& primary cell culture}

HL-1 cells were grown in Claycomb medium (SigmaAldrich) supplemented with 10\% FBS (Sigma- 
Aldrich), $1 \%$ penicillin-streptomycin (Pen-Strep $10000 \mathrm{U} / \mathrm{ml}$, Lonza), $1 \%$ ultraglutamine 1 (200 mM, Lonza) and $1 \mathrm{mM}$ norepinephrine (Sigma-Aldrich) in gelatin/fibronectin precoated T75 flasks. After reaching full confluence, cells were split 1:3 according to Dr Claycomb's instructions [20]. Adult cardiomyocytes were isolated as previously described [21,22].

\section{Trypan blue assay}

HL-1 cells were seeded at $10 \times 10^{4}$ cells/well in precoated 24 -well plates $\left(1 \mathrm{~h}, 37^{\circ} \mathrm{C}\right)$. All experiments were performed in triplicate. The day after seeding, HL-1 cells were washed with PBS $1 \times$ and treated with different doses of CaP-NPs, ranging from 500 to $3.9 \mu \mathrm{g} /$ $\mathrm{ml}$. After $24 \mathrm{~h}, \mathrm{HL}-1$ cells were collected with trypsinEDTA, resuspended in Claycomb complete medium and counted in a Trypan blue solution (Sigma-Aldrich). The percentage of dead cells over total number of cells was calculated.

\section{Viability, cytotoxicity \& caspase 3-7 assays}

HL-1 cells or freshly isolated adult cardiomyocytes were seeded at $1 \times 10^{4}$ cells/well density in precoated 96-well plates $\left(1 \mathrm{~h}, 37^{\circ} \mathrm{C}\right)$, and different doses of CaP-NPs were administered as specified in the text. All experiments were performed in triplicate. Viability, cytotoxicity and caspase-3/7 activities were measured using the ApoToxGlo triplex Assay (Promega ${ }^{\mathrm{TM}}$ ), according to the manufacturer's instructions. Fluorescence and bioluminescence reactions were measured using a Synergy ${ }^{\mathrm{TM}} \mathrm{H} 4$ Hybrid Multi-Mode Microplate Reader (BioTek).

\section{Inhibition of endocytosis}

Clatrin inhibitor (PitStop2, abcam) and dynamin inhibitor (MiTMAB, abcam) were used at $1 \mu \mathrm{M}$. After 30 min incubation at $37^{\circ} \mathrm{C}$, cells were treated with CaP-NPs for $24 \mathrm{~h}$ and processed as described in the text.

\section{RNA isolation \& quantification}

Total RNA was extracted using PureZol Reagent (Biorad). Reverse transcription of RNA for miR-133, cel-miR-39 and U6 was performed using the miRCURYLNA ${ }^{\text {TM }}$ Universal RT microRNA PCR Polyadenylation and cDNA synthesis kit (Exiqon). Quantitative polymerase chain reaction was performed with microRNA LNA ${ }^{\mathrm{TM}}$ PCR primers (Exiqon) using the

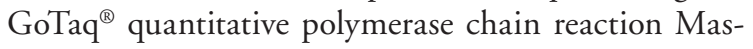
ter Mix (Promega). Relative expression was calculated using the $\Delta \Delta(\mathrm{Ct})$ method.

\section{Luciferase assay}

The miR-133 luciferase sensor [22] was transfected into HEK-293 cells using Lipofectamine 2000 (Invi- trogen), following the manufacturer's protocol. After $5 \mathrm{~h}$, cell medium was changed and miRNA-loaded CaP-NPs added to the medium. $6 \mathrm{~h}$ post-treatment, cells were lysed and luciferase activity was measured as described by the manufacturer (Promega).

\section{Confocal microscopy}

HL-1 cells were seeded at $5.0 \times 10^{4}$ cells/well on VWR Micro cover slips coated with gelatin/fibronectin in complete Claycomb medium, and then incubated overnight at $37^{\circ} \mathrm{C}, 5 \% \mathrm{CO}_{2}$. The following day, HL-1 cells were treated with CaP-NP-FITC. $24 \mathrm{~h}$ post-treatment, cultured cells were fixed using $4 \%$ paraformaldehyde at room temperature, followed by treatment in phosphate-buffered saline (PBS) containing $0.2 \%$ Triton X-100 for $5 \mathrm{~min}$. After three washes with PBS, nuclei were counterstained with 4,6-diamidino-2-phenylindole, dihydrochloride, Life Technology for $5 \mathrm{~min}$ at room temperature. Fluorescent images were taken with a laser scanning confocal microscope (Olympus, FV1000/SIMS) [21].

\section{Patch-Clamp recordings}

Electrophysiological parameters of HL-1 cells and primary ventricular cardiomyocytes freshly isolated from adult mouse were measured using standard wholecell voltage-clamp and patch-clamp techniques. Experiments were conducted at room temperature. Patch pipette filling solution contained (in $\mathrm{mmol} / \mathrm{l}$ ): K-aspartate 120, $\mathrm{NaCl}$ 10, $\mathrm{MgATP} 3, \mathrm{CaCl}_{2}$ 1, EGTA 10 and Hepes $5(\mathrm{pH} 7.2)$ with a free cytosolic $\mathrm{Ca}^{2+}$ concentration of $10-8 \mathrm{M}$. Analog signals were amplified, digitized $(2.8 \mathrm{kHz})$ and filtered $(1 \mathrm{kHz})$ with an MultiClamp 700B patch-clamp amplifier integrated with an Axon's Digidata 1440A AD/DA interface and stored on a computer for off-line analysis using Clampfit v.10.3. Experimental protocols were controlled using Clampex software (version 10.3 of pClamp, Axon Instruments). Pipette resistances ranged from 2 to $3 \mathrm{MOhm}$ and pipette potentials were zeroed before cell contact. Liquid junction potential corrections calculated by the pClamp software were performed off-line after experiments. Preparations were superfused with Hank's balanced salt solution ( $\mathrm{pH} 7.40$, buffered with $10 \mathrm{mmol} / \mathrm{l}$ Hepes) at 2-3 $\mathrm{ml} / \mathrm{min}$ at RT. Seal resistances were 2-10 GOhm. Rupturing the cell membrane in the patch resulted in access resistances of 2-10 MOhm. Clampex patchclamp amplifier allowed series resistances (70-90\%) and whole cell capacitances electronic compensation. Action potentials (APs), resting membrane potential, input resistance $\left(\mathrm{R}_{\mathrm{in}}\right)$, membrane capacitance $\left(\mathrm{C}_{\mathrm{m}}\right)$ as well as sodium $\left(\mathrm{I}_{\mathrm{Na}}\right)$, calcium $\left(\mathrm{I}_{\mathrm{Ca}, \mathrm{L}}\right)$ and net membrane currents (NMCs) were measured in both single 
HL-1 and adult ventricular cardiomyocytes in current- and voltage-clamp modes. Resting membrane potential was measured in current-clamp modality, applying $10 \mathrm{~s}$ long current stimuli with the current value set to zero $(\mathrm{pA}=0) . \mathrm{C}_{\mathrm{m}}$ was measured utilizing a sinusoidal voltage stimulus and processing the resulting sinusoidal current using a phase-sensitive detector or 'lock-in amplifier' implemented either in Clampex hardware or software. $\mathrm{R}_{\text {in }}$ was calculated from voltage changes in response to $5 \mathrm{pA}$ hyperpolarizing current steps from holding potentials. APs from which parameters as AP threshold (APTh), amplitude (APA), duration $\left(\mathrm{APD}_{90}\right)$ and maximal upstroke velocity $(\mathrm{dV} /$ $\left.\mathrm{dt}_{\max }\right)$ were measured, were elicited with depolarizing current steps of $10 \mathrm{pA}(3 \mathrm{~ms})$ until threshold-APs were obtained. Threshold-Aps were after repeated 10 -times at a rate of $1 \mathrm{~Hz}$ and the $10^{\text {th }} \mathrm{AP}$ used for measurements.

To study the effect of NPs on $\mathrm{I}_{\mathrm{Na}}, \mathrm{I}_{\mathrm{ca}, \mathrm{L}}$ and NMCs of HL-1 cells and adult ventricular cardiomyocytes, standard step protocols and downward directed ramp were applied. In downward directed ramp protocols, the membrane was clamped from 50 to $-110 \mathrm{mV}$ over $5000 \mathrm{~ms}\left(32 \mathrm{mV} \mathrm{s}^{-1}\right.$ in order to inactivate voltage gated ion channels) from a holding potential of $-80 \mathrm{mV}$ for two-times at a rate of $0.1 \mathrm{~Hz}$ and $\mathrm{I}_{\mathrm{C}, \mathrm{L}}$ was blocked by addition of $0.2 \mathrm{mM}$ nifedipine. To obtain sodium current I-V relationships, $100 \mathrm{~ms}$ long voltage steps were applied, ranging from -90 to $65 \mathrm{mV}$ from a holding potential of $-80 \mathrm{mV}$ at a rate of $0.33 \mathrm{~Hz}$. Calcium I-V relations were obtained by measuring activated currents at different test potentials $(300 \mathrm{~ms}$, from -30 to $75 \mathrm{mV}$ at a rate of $0.25 \mathrm{~Hz}$ ) from a holding potential of $-40 \mathrm{mV}$. Steady-state activation curves were derived from each I/V relation and were described by fitting experimental points with the Boltzmann equation. To take into account the variations in cell size, current amplitude were normalized to $\mathrm{C}_{\mathrm{m}}$ through all measurements. In sodium current experiments, the patch pipette filling solution, and the Hank's balanced salt solution were properly modified in order to bypass technical issues related to the capacity of the patch-clamp amplifier to track the fast sodium change in current and series resistance. Patch-clamp current and voltage traces were acquired at least at $5 \mathrm{kHz}$, depending on the protocol applied.

\section{Cardiomyocyte contractility \& $\mathrm{Ca}^{2+}$ transient recordings}

Adult cardiomyocytes and HL-1 cells were loaded with $1 \mu \mathrm{M}$ Fura-2 acetoxymethyl (ThermoFischer Scientific), field stimulated at $1.0 \mathrm{~Hz}$ and recorded using an IonOptix System (Milton, MA, USA), as previously described [21].

\section{Statistics}

Values are given as mean $\pm \mathrm{SD}$. Data were compared using the two-tailed Student $t$-test or Two-Way ANOVA and Bonferroni Test. Differences between data sets were considered significant at $\mathrm{p}<0.05$. All data were analyzed using Prism 6.0 software (GraphPad Software, Inc.).

Mice

All procedures on mice were performed according to institutional guidelines in compliance with national (D.L. N.26, 04/03/2014) and international law and policies (new directive 2010/63/EU). The protocol was approved by the Italian Ministry of Health. Special attention was paid to animal welfare and to minimize the number of animals used and their suffering. All experiments were performed on 10-week-old C57B6J male mice. Solutions were administered by retro-orbital administration as described elsewhere [23].

\section{Results \& discussion}

\section{Synthesis \& characterization of CaP-NPs}

Living organisms adopt complex biomineralization processes to produce nanostructured materials endowed with high biocompatibility and stability [24]. These nanomaterials, when synthetically prepared with chemical-physical features very close to the biogenic ones, can therefore be ideal systems for biomedical applications, particularly as nanocarriers for drug delivery [25,26]. Synthetic biomimetic CaP-NPs, which resemble the main inorganic component of bones, teeth and also some pathological calcification, show high biocompatibility and $\mathrm{pH}$-sensitive stability that facilitates the complete release of payload upon dissolution in biological acidic environments such as endosomes and lysosomes [27-29]. The complete dissolution of $\mathrm{CaP}$ in its ionic constituents $\left(\mathrm{Ca}^{2+}\right.$ and $\left.\mathrm{PO}_{4}^{3-}\right)$ prevents undesirable NP accumulation in cells and tissues, a drawback often encountered with other inorganic and metallic NPs [30]. Based on this evidence, we generated CaP-NPs using a one-pot synthesis method, in which the biocompatible organic molecule citrate plays a relevant role in the mechanism of $\mathrm{CaP}$ crystallization. The benefit of citrate-based synthesis concerns the stabilization of CaP-NPs at the early stage of crystallization, which is due to the binding of citrate ions to the $\mathrm{CaP}$ surface. In fact, whereas a broad distribution in particle size is obtained when calcium and phosphate are mixed in solution in the absence of crystal-growth inhibitor, the adjustment of the citrate amount in solution allowed us to control morphology, crystallinity and size of CaP-NPs [31]. Notably, a similar effect might occur in vivo in bones where citrate interacting at the surface of biogenic apatite nanocrystals (citrate 
accounts for about $5.5 \mathrm{wt} \%$ of the total organic component of bone tissue) can limit their further growth and renders the mineral surface more hydrophobic to interact with collagen [31,32].

DLS was used to monitor the effect of citrate on size and colloidal stability of CaP-NPs. Mean particle size (reported as $\mathrm{Z}$-average) as well as count rate of the reaction medium were continuously recorded for $60 \mathrm{~min}$. As shown in Figure 1A, incremental doses of sodium citrate $\left(\mathrm{Na}_{3} \mathrm{Cit}\right)$ significantly limited the growth of CaP-NPs, as evidenced by the slow increase in the mean particle size as a function of the crystallization time. Moreover, higher $\mathrm{Na}_{3} \mathrm{Cit}$ concentrations also improved the colloidal stability of NPs as shown Figure $1 \mathrm{~B}$ where the count rate of $\mathrm{CaP}-\mathrm{NPs}$ prepared in the presence of 40 and $80 \mathrm{mM}$ of $\mathrm{Na}_{3}$ Cit remained nearly constant for $60 \mathrm{~min}$ compared with conditions at 0 and $20 \mathrm{mM} \mathrm{Na}_{3}$ Cit. These results confirmed that no sedimentation occurred. Therefore, an initial $\mathrm{Na}_{3}$ Cit concentration of $80 \mathrm{mM}$ was selected for the further studies since it gave the best results in terms of size and colloidal stability of CaP-NPs.

The next step was to determine the most suitable time for crystallization through the evaluation of the chemical structure, size and surface charge of CaP-NPs. At determined crystallization times ranging from 5 to $30 \mathrm{~min}$, CaP-NPs were washed three-times by centrifugation, freeze-dried and then analyzed by Fourier Transform Infrared spectroscopy (FT-IR) and DLS. Figure $1 \mathrm{C}$ displays the FT-IR spectra of CaP-NPs crystallized at different times showing the typical bands of $\mathrm{CaP}$ compound (i.e., $\mathrm{PO}_{4}^{3-}$ vibration bands at 560-603 $\left[v_{4}\right], 962\left[v_{1}\right]$ and $\left.1000-1104 \mathrm{~cm}^{-1}\left[v_{3}\right][33]\right)$. Moreover, since the synthesis was not carried out under inert gas, FT-IR spectra exhibited bands at $870\left(v_{2}\right)$ and 1420 $\mathrm{cm}^{-1}\left(v_{3}\right)$ assignable to $\mathrm{CO}_{3}^{2-}$ vibrations, which are characteristic for non-apatitic carbonates and $\mathrm{B}$-type carbonate substitution $\left(\mathrm{CO}_{3}\right.$ substitution for $\left.\mathrm{PO}_{4}^{3-}\right)$, respectively [33]. The band at $c a .1600 \mathrm{~cm}^{-1}$, assignable to citrate $\left(v_{\text {as }} \mathrm{OCO}\right)[33]$, was also clearly visible in all samples. In addition, the narrowing of the bands at $560-603 \mathrm{~cm}^{-1}$ revealed that amorphous $\mathrm{CaP}$ turned into a more crystalline state, following a time-dependent process. The amorphous to crystalline transformation was quantitatively evaluated by means of the splitting factor (Table 1), a well-reported index for the evaluation of crystallinity degree of CaP-based materials [34]. Additionally, while an increase in CaP-NP size was observed as a function of crystallization time, no significant variation was found for $\zeta$-potential and polydispersity index (PDI), which remained stable under all conditions (Table 1). In particular, $\zeta$-potential values were negative, indicating that citrate covered the surface of NPs, thus providing a negative surface charge.
To remove any unreacted ions after 5 min of crystallization, which gave the most promising results in terms of size of CaP-NPs for the further application as drug-delivery system, we applied a dialysis step that, in contrast to other purification procedures, such as centrifugation and freeze-drying or even purification by desalting columns, prevents some irreversible agglomeration of adjacent particles. Thus, the removal of unreacted ions was assessed by measuring the conductivity of the dialysis medium (outside the membrane) as a function of time, which showed a plateau after $6 \mathrm{~h}$ of treatment (Supplementary Figure 1A). This conductivity plateau indicated that the equilibrium of ionic exchange from the reaction medium to the dialysis medium was reached and a large majority of the unreacted ions were removed. Z-average, PDI and $\zeta$-potential of CaP-NPs after $6 \mathrm{~h}$ of dialysis were 129 $\pm 2 \mathrm{~nm}, 0.18 \pm 0.10$ and $-31.5 \pm 1.5 \mathrm{mV}$, respectively. These results indicated that dialysis, in contrast to the washing step via centrifugation (data not shown), drastically decreased the mean size of CaP-NPs as well as narrowed size distribution (low PDI) while preserving a constant negative $\zeta$-potential, which is a fundamental prerequisite for the use of nanocarriers in excitable cardiac cells [19]. In addition, the stability of CaP-NPs after washing by dialysis was evaluated by DLS measurements for $300 \mathrm{~min}$ (Supplementary Figure 1B). A constant particle size as well as mean count rate demonstrated that neither aggregation nor sedimentation occurred.

Finally, morphological analysis by TEM revealed CaP-NPs as round shape particles of about $20-50 \mathrm{~nm}$ in diameter (Figure 1D). The smaller size determined by TEM in comparison to that quantified by DLS is consistent with the ability to analyze the dried solid material diameter via the TEM technique in contrast to DLS, which gives the hydrodynamic size distribution in suspension of solid particle, organic layers and surrounding liquid. Moreover, selected area electron diffraction (SAED) pattern (Figure 1D, inset) confirmed their amorphous nature (i.e., presence of diffuse rings rather than spots) while energy dispersive $\mathrm{X}$-ray analysis (Supplementary Figure 1C) corroborated their chemical composition (i.e., presence of $\mathrm{Ca}$ and $\mathrm{P}$ together with $\mathrm{C}, \mathrm{O}$ and $\mathrm{Cu}$ from the cooper grid coated with carbon/formvar support film).

\section{CaP-NP biocompatibility \& cellular internalization}

Our next objective was to test the biocompatibility of optimized CaP-NPs by subjecting HL-1 cardiac cells to incremental doses of CaP-NPs $(0-500 \mu \mathrm{g} /$ $\mathrm{ml}$ ). As demonstrated by Trypan blue exclusion assay (Figure 2A), HL-1 cells largely tolerated an acute 

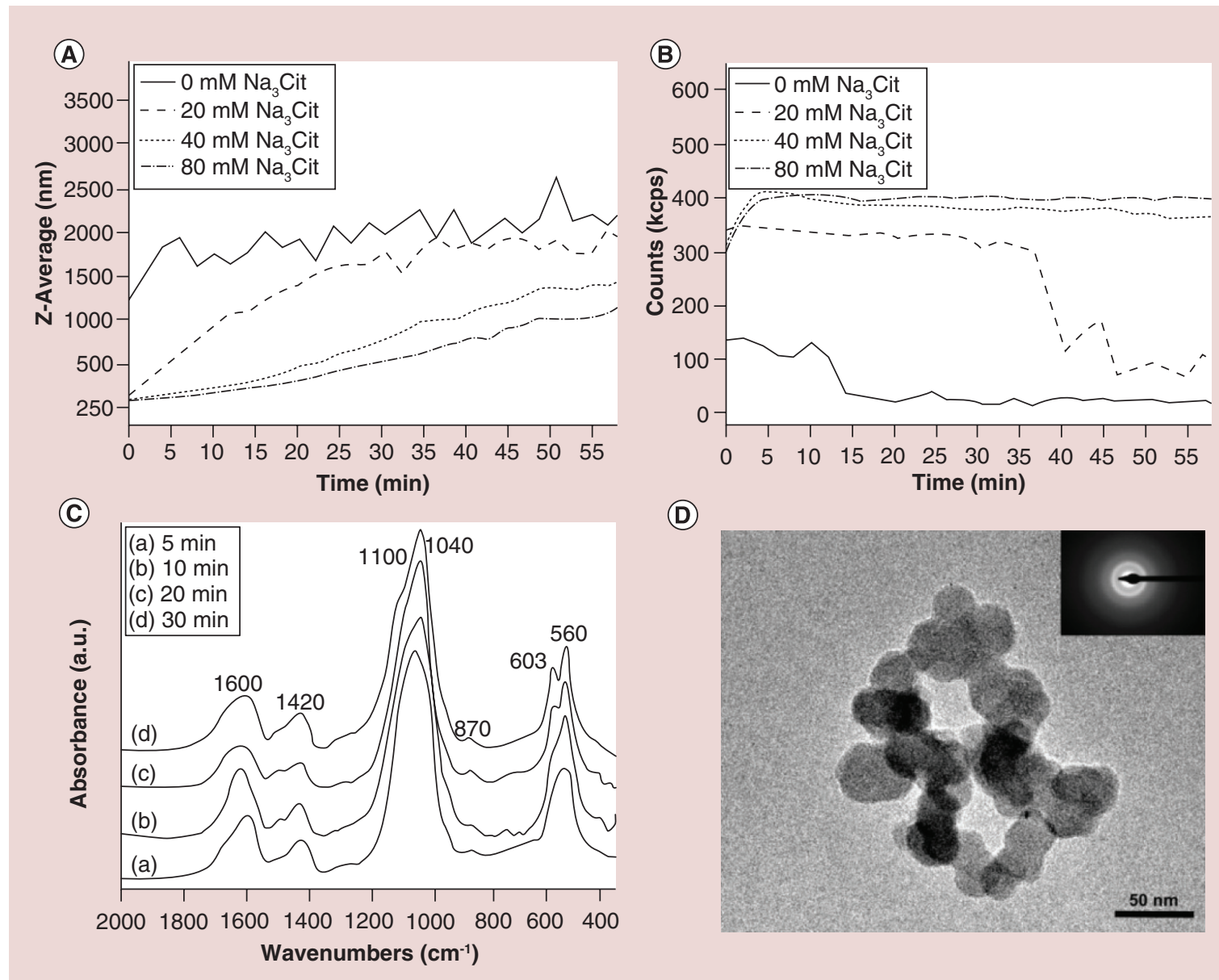

(D)

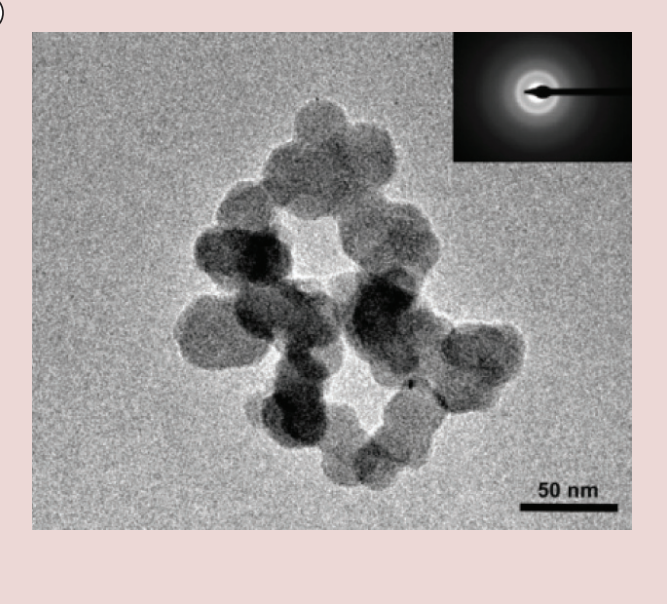

Figure 1. Chemical-physical and morphological characterization of CaP-NPs.(A) Mean particle size (Z-average) and (B) count rate (counts) as a function of time, analyzed by DLS during CaP-NPs crystallization in the absence $(0 \mathrm{mM})$ and presence of $\mathrm{Na}_{3} \mathrm{Cit}$ at different concentrations. (C) FT-IR spectra of CaP-NPs prepared in the presence of $\mathrm{Na}_{3} \mathrm{Cit}(80 \mathrm{mM})$ at different crystallization times (i.e., 5, 10, 20 and $\left.60 \mathrm{~min}\right)$. (D) TEM image of CaP-NPs. Inset: corresponding SAED pattern.

DLS: Dynamic light scattering; SAED: Selected area electron diffraction; TEM: Transmission electron microscopy.

administration of CaP-NPs, showing an increase in mortality rate only at higher doses $(>125 \mu \mathrm{g} / \mathrm{ml})$ and $24 \mathrm{~h}$ postadministration. This finding was further supported by a viability, cytotoxicity and caspase 3-7 assay, which showed a significant increased levels of apoptotic activity only with chronic administration of higher concentrations $(\geq 250 \mu \mathrm{g} / \mathrm{ml})$ of CaP-NPs (Figure 2B \& Supplementary Figure 2). We tested bio-

\begin{tabular}{|c|c|c|c|c|}
\hline $\begin{array}{l}\text { Crystallization time } \\
\text { (min) }\end{array}$ & $\mathbf{S F}^{\dagger}$ & Z-average $(\mathrm{nm})$ & PDI & $\zeta$-potential (mV) \\
\hline 5 & No calculable & $1175 \pm 110$ & $0.55 \pm 0.03$ & $-26.9 \pm 0.6$ \\
\hline 10 & 1.76 & $1656 \pm 408$ & $0.52 \pm 0.03$ & $-25.9 \pm 0.9$ \\
\hline 20 & 2.16 & $2405 \pm 402$ & $0.38 \pm 0.02$ & $-26.1 \pm 0.7$ \\
\hline 60 & 2.25 & $3376 \pm 851$ & $0.44 \pm 0.02$ & $-30.4 \pm 1.3$ \\
\hline
\end{tabular}


compatibility also on adult cardiomyocytes subjected to the same dose/responses for CaP-NPs and no differences were observed (Supplementary Figure 3). Based on these results, a concentration of $20 \mu \mathrm{g} / \mathrm{ml}$ was chosen for the subsequent studies.

Cellular internalization was evaluated by exposing HL-1 cells to CaP-NPs conjugated to the fluorescein isothiocyanate (FITC). Confocal microscopy revealed distinct vesicular compartmentation, confirming the internalization of CaP-NP-FITC (Figure 2C). To determine whether the internalization was due to active mechanisms of endocytosis, specific inhibitors of clathrin and dynamin, which are involved in the initial processes of endocytosis and invagination from the plasma membrane, were used. Following pretreatment with these inhibitors, HL-1 cells were exposed to increasing concentrations of CaP-NPs, and a Trypan blue exclusion assay was performed as described above. In accordance with our previous studies of negativecharged NPs [35], inhibition of dynamin- and clathrinmediated endocytosis significantly reduced cellular toxicity at all doses of CaP-NPs, suggesting that internalization occurs via conventional clathrin- and dynamin-mediated endocytosis (Figure 2A). Altogether, the above findings demonstrate that CaP-NPs efficiently internalize into the cytoplasmic intracellular space of cardiac cells without inducing toxicity or apoptosis.

\section{Effects of CaP-NPs on cardiomyocyte function}

One of the main concerns in using calcium-based NPs is their potential interference with functional properties of excitable and contractile cells, such as cardiomyocytes. Thus, to evaluate any potential effect that $\mathrm{CaP}-$ NPs might have on cellular physiological properties and functions, a complete electrophysiological evaluation was performed on HL-1 cells as well as primary ventricular cardiomyocytes freshly isolated from adult mouse. To this end, HL-1 and adult cardiomyocytes were exposed to $20 \mu \mathrm{g} / \mathrm{ml}$ of CaP-NPs for $24 \mathrm{~h}$ (chronic stimulation) or $5 \mathrm{~h}$ (acute stimulation), respectively. As shown in Supplementary Figure 4, results from voltageclamp experiments showed no effect of CaP-NPs on any of the typical characteristics of cell excitability, including membrane potential $\left(\mathrm{V}_{\mathrm{m}}\right)$, membrane capacitance $\left(\mathrm{C}_{\mathrm{m}}\right)$, membrane resistance $\left(\mathrm{R}_{\mathrm{m}}\right)$, threshold of the AP, AP amplitude (APA), maximum speed of ascent of

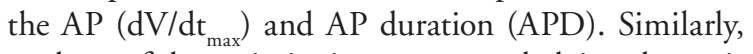
analyses of the main ionic currents underlying the typical cardiac cell AP (sodium, calcium and potassium currents measured by appropriate steps and ramp protocols) showed no significant differences between controls and treated cells under both chronic (Figure 3) and acute conditions (Figure 4). Ramps protocols shown in Figures $3 A$ \& $4 A, B$ were used to measure NMCs which represent the activation of at least three time independent or slowly activating $\mathrm{K}^{+}$currents $\left(\mathrm{I}_{\mathrm{K} 1}, \mathrm{I}_{\mathrm{Kr}}\right.$ and $\left.\mathrm{I}_{\mathrm{Ks}}\right)$ [36].

Finally, we evaluated adult cardiomyocyte contractility and intracellular calcium transients, a process associated with the excitation-contraction coupling of cardiac cells [37]. As shown in Supplementary Table 1, no significant alterations were found between treated and untreated conditions, further supporting the
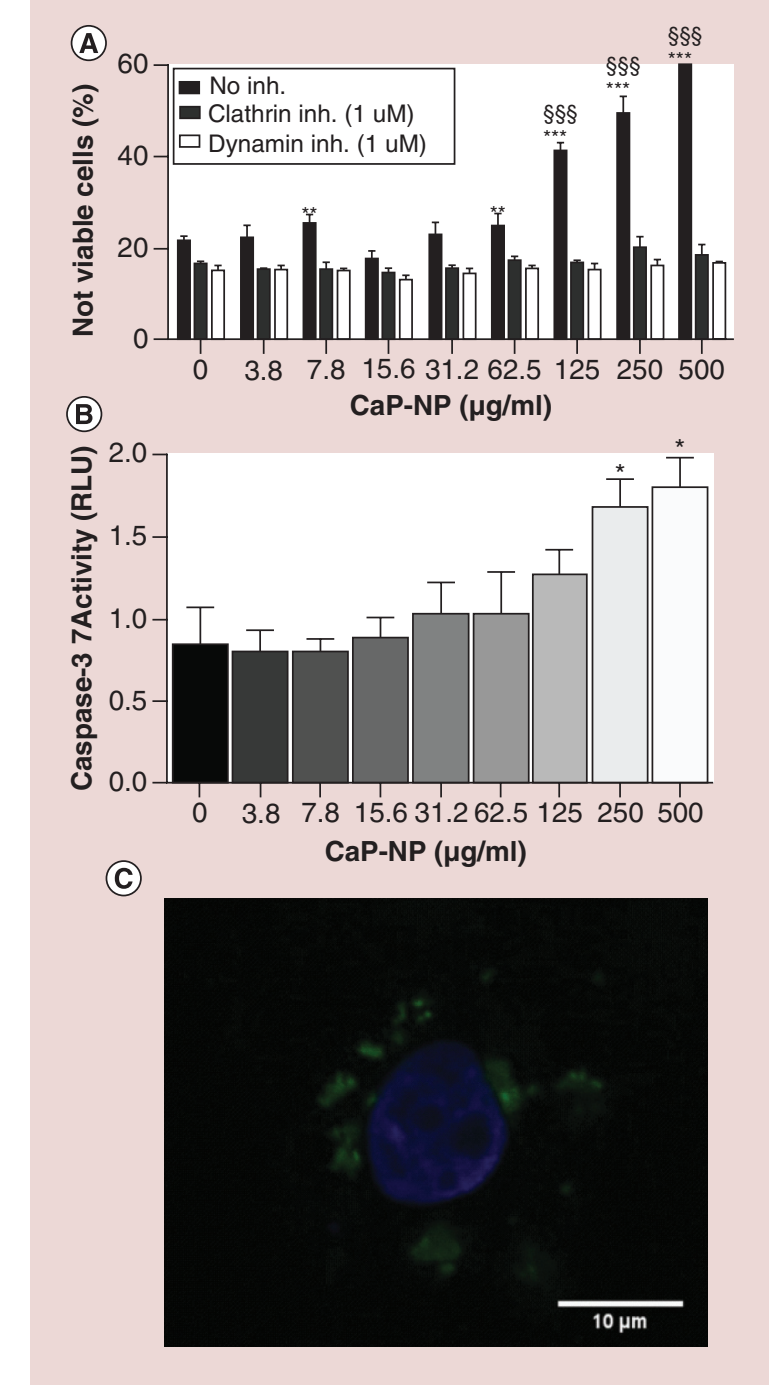

Figure 2. Biocompatibility of HL-1 cardiac cells to CaP-NPs. (A) Cell toxicity as measured by Trypan blue exclusion assay in $\mathrm{HL}-1$ cells treated as indicated. (B) Apoptosis detection via activated caspase 3 and 7 assay in $\mathrm{HL}-1$ cells treated with increasing concentration of CaP-NPs. (C) Cellular internalization of FITC-conjugated CaP-NPs (green); nucleus (blue). ${ }^{\S \S \S} p<0.001$ compared with conditions of no CaP-NP treatment (NT) using Two-way Anova followed by Dunnet's multiple comparison test.

${ }^{*} p<0.05 ;{ }^{* *} p<0.005 ; * * * p<0.001$ calculated for each CaP-NP dose using Two-way Anova followed by a Bonferroni's test. 

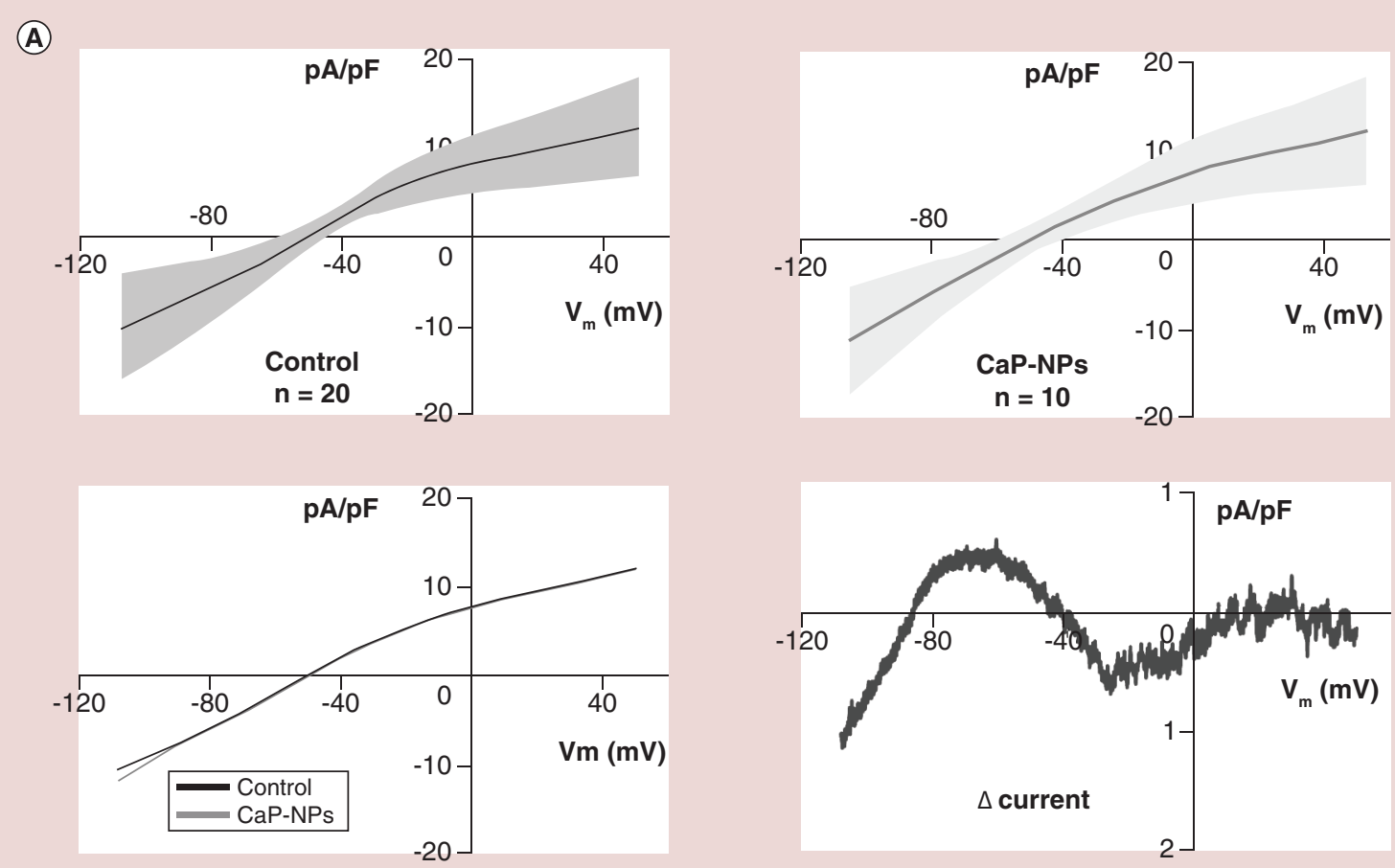

(B)
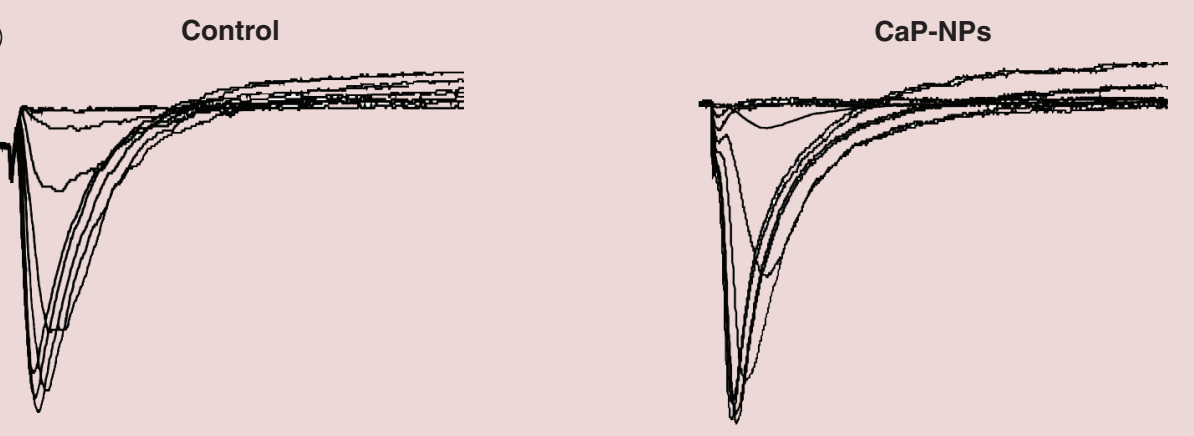

(C)
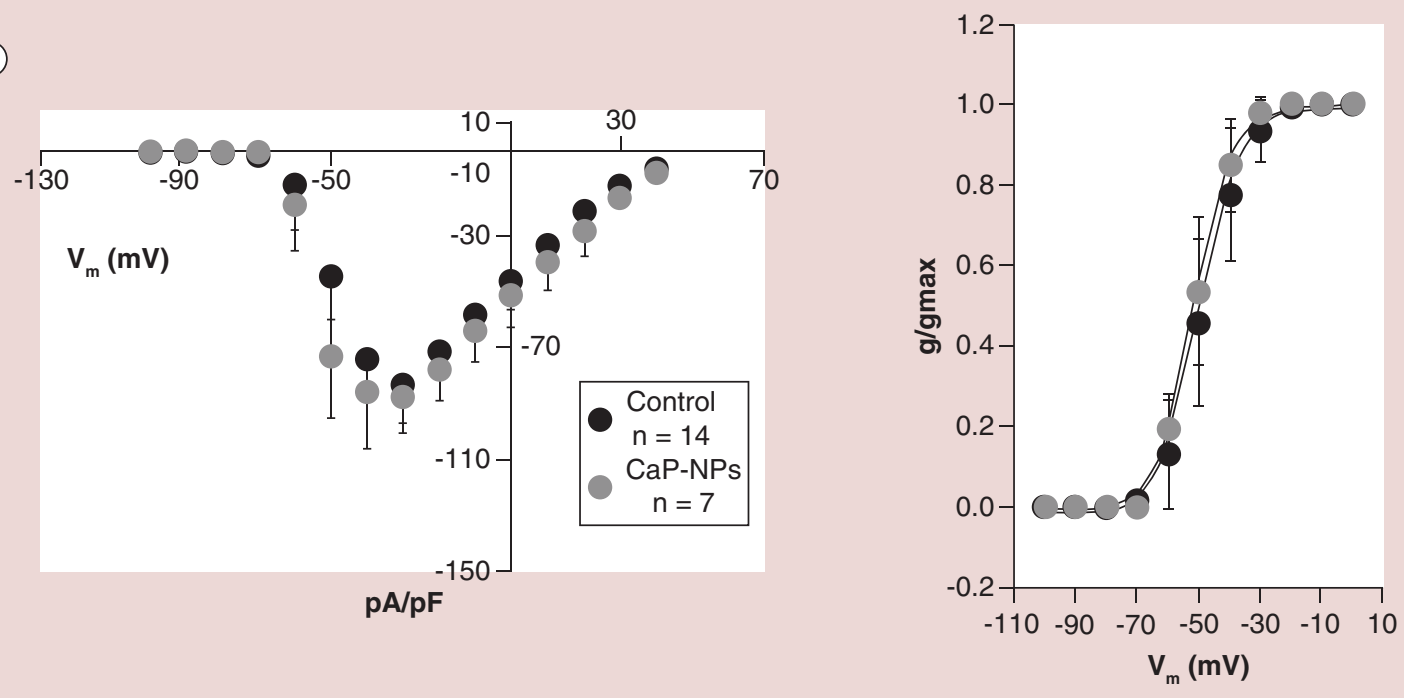

Figure 3. Voltage-current relationship (I-V curve) in HL-1 cells exposed to CaP-NPs. (A) Top row. Net membrane current I-V curves for control (left, black) and exposed (right, gray) HL-1 cells. Bottom row. Superimposition of the two curves (left) and net membrane current difference curve (right). (B) Sodium current traces for both conditions. Bottom. I-V curve for sodium currents and voltage dependency of sodium channel activation $\left(\mathrm{g} / \mathrm{g}_{\max }\right.$ right) for control (black) and exposed (gray) HL-1 cells. 


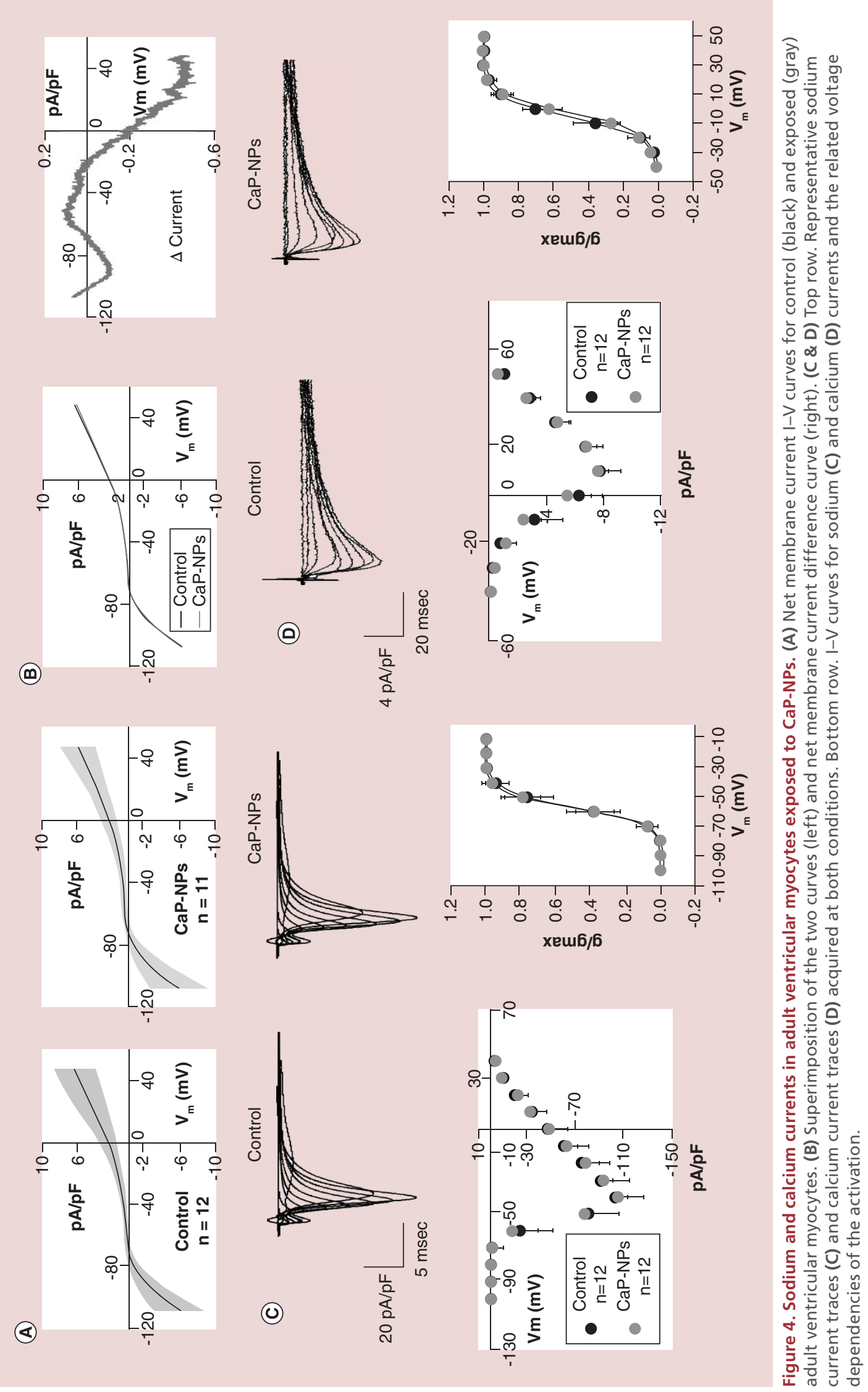


(A)

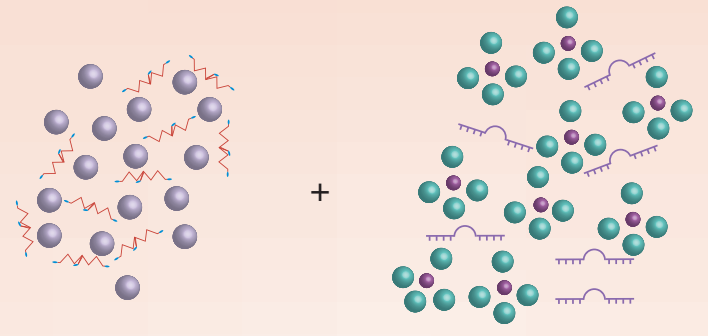

Solution $\mathrm{A}: \mathrm{Ca}^{2+}+\mathrm{Cit}$

Solution $\mathrm{B}: \mathrm{PO}_{4}{ }^{3-}+$ miRNA

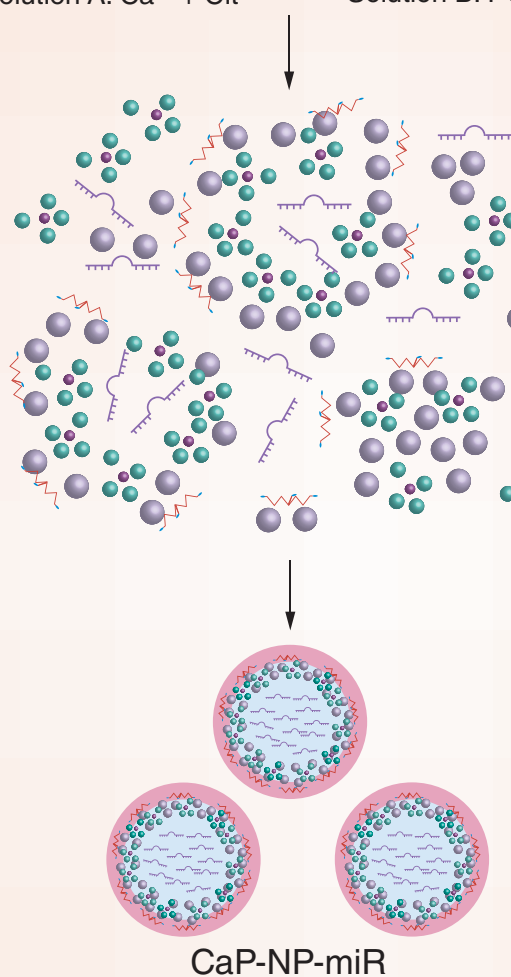

(B)

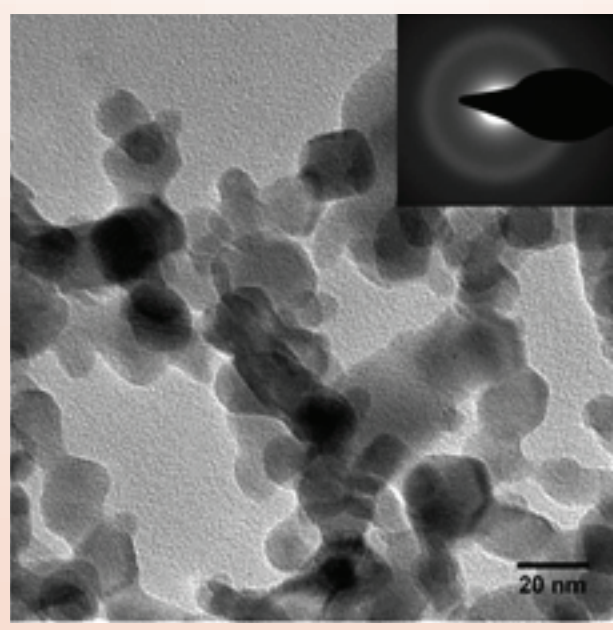

Figure 5. CaP-NP-miR assembly. (A) Schematic illustration of the formation mechanism of CaP-NP-miRs. (B) TEM images of CaP-NP-miRs; inset: corresponding SAED pattern.

SAED: Selected area electron diffraction. 
Table 2. Z-average, polydispersity index and $\zeta$-potential of CaP-NP-miRs, as a function of miRNA concentration added during nanoparticle synthesis.

\begin{tabular}{|llll|}
\hline miRNA $\left(\mu \mathbf{~ m l}^{-1}\right)$ & Z-average $(\mathbf{n m})$ & PDI & $\zeta$-potential $(\mathbf{m V})$ \\
0 & $129 \pm 2$ & $0.18 \pm 0.10$ & $-31.5 \pm 1.5$ \\
\hline 1 & $156 \pm 6$ & $0.23 \pm 0.10$ & $-29.6 \pm 2.6$ \\
5 & $199 \pm 11$ & $0.20 \pm 0.05$ & $-36.6 \pm 1.6$ \\
\hline 10 & $225 \pm 6$ & $0.17 \pm 0.05$ & $-32.1 \pm 3.0$ \\
\hline PDI: Polydispersity index. & & & \\
\hline
\end{tabular}

evidence that administration of CaP-NPs does not alter cellular functional properties of cardiac cells. Similarly, no significant alterations in intracellular calcium transients were found in HL-1 treated cells (Supplementary Table 2).

Taken together, these findings indicate good biocompatibility of CaP-NPs for cardiac cells, suggesting their potential use as drug nanocarriers for CVDs.

\section{CaP-NPs encapsulate \& deliver miRNAs into cardiac cells}

We next asked whether CaP-NPs can efficiently bind synthetic compounds (e.g., miRNAs) and thus potentially be used as effective nanocarriers for intracellular drug delivery. For this purpose, different amounts of synthetic unmodified and unprotected miRNA duplexes (ranging from 1 to $10 \mu \mathrm{g} \mathrm{ml}^{-1}$ ) were added to the reaction medium during the one-pot CaP-NP synthesis protocol described above. DLS analysis revealed that the size of CaP-NP-miRNAs (CaP-NPmiRs) increased as a function of miRNA amount, while PDI values and surface charge remained close to those of miRNA-free CaP-NPs (Table 2). The increase in size could be associated with an effective interaction of miRNAs with CaP-NPs, while unaltered surface charge and PDI indicated that also in this case citrate homogenously covered the NP surface. A scheme of a possible formation mechanism of CaP-NP-miRs is shown in Figure 5A. TEM analysis of CaP-NP-miRs (Figure 5B) revealed round shape NPs of approximately 20-30 $\mathrm{nm}$ in diameter similar to miRNA-free CaPNPs. In addition, the presence of diffuse rings in the SAED pattern of CaP-NP-miRs (Figure 5B, inset) validated their amorphous nature, suggesting that the presence of miRNA under these experimental conditions did not induce or accelerate the crystallization mechanism of CaP-NPs.

To evaluate the efficiency of miRNA delivery, we exposed HL-1 cells to CaP-NP-miRs (carrying either the muscle-enriched miR-133 or the not-mammalian $C$. elegans cel-miR-39-3p) and measured intracellular levels of miRNAs at different time points post-treatment. For these experiments CaP-NP-miRs were prepared using the maximum initial concentration of miRNA. As shown in Figure 6A \& B, qRT-PCR analyses of total RNA revealed an effective time-dependent increase in the levels of intracellular delivered miRNA, confirming the effective encapsulation of both miRNAs into CaPNPs as well as their cellular uptake. A similar result of CaP-NP-mediated uptake of miRNA was confirmed in adult cardiomyocytes (Supplementary Figure 5). Additionally, a cell-based luciferase assay confirmed that the administered CaP-NP-miR-133 efficiently repressed an miR-133-specific target [22] (Figure 6C).

Altogether, our findings provide evidence that functionalized CaP-NPs possess an intrinsic ability to carry functional miRNAs into cardiac cells.

\section{Uptake of CaP-NP-miRs in vivo}

As a final step, we evaluated as a proof of concept the in vivo efficiency of CaP-NPs as drug-delivery system. In particular, CaP-NP-miRs (complexed with the exogenous cel-miR-39-3p) were administered to 10 -week-old mice by retro-orbital injection (once a day for three consecutive days), whereafter qRT-PCR analyses were performed on total RNA isolated from various tissues. As shown in Figure 7, a significant accumulation of cel-miR-39-3p was found in the left ventricle as well as liver, spleen and kidney, whereas no signals were detected in brain, likely due to the high filtering efficiency of the hematic-encephalic barrier. These results demonstrate the capacity of our formulation for intracellular drug-delivery in vivo.

\section{Discussion}

In this report, a novel and safe drug-delivery system based on bioinspired negatively charged CaP-NPs was generated. To the best of our knowledge this represents the first cross-domain study that, ranging from functional chemistry to molecular and cellular cardiac physiology, provides important advances in the field of cardiovascular nanomedicine.

When selecting suitable nanocarriers for drug delivery, several concerns hindering the potential clinical translation of NPs (i.e., the biodegradability of the materials, the toxicity of degradation byproducts, the 


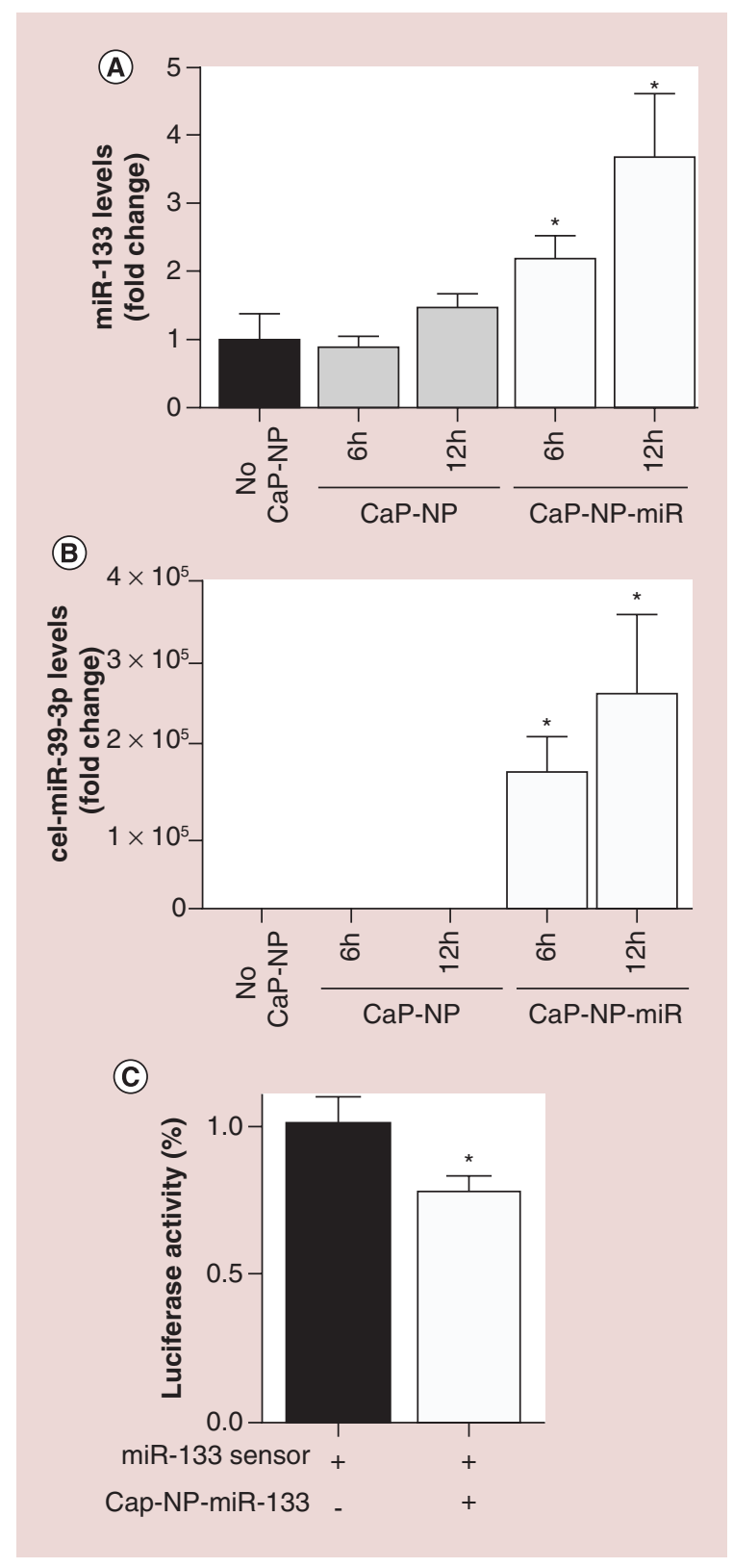

Figure 6. In vitro CaP-NP delivery into a cardiac cell line. (A \& B) qRT-PCR on HL-1 cells treated for 6 and $12 \mathrm{~h}$ with CaP-NP-miRs loaded with miR-133a (up) and cel-miR-39-3p (down). (C) Luciferase reporter activity measured on HEK-293 cells transfected with a luciferase sensor and treated for $6 \mathrm{~h}$ with CaP-NP-miR carrying miR-133.

toxic structural features of NPs and protection of the payload) need to be taken into account [38]. CaP, a synthetic carrier resembling biogenic compounds, has ideal properties of biocompatibility, bioresorbability and biodegradability because of its structural and chemical similarity with the mineral component of bones and teeth [39]. Furthermore, CaP-based carriers provide the further improvement of nonimmunogenicity and minimal or absent toxicity $[27,28]$.
An additional advantage of CaP-NPs is related to the fact that at acidic $\mathrm{pH}$, as found in endosomes and lysosomes after cellular intake, these nanocarriers rapidly dissolve into their ionic constituents facilitating the release of their cargo into the cytoplasm without any residual accumulation in cells and tissues, a critical drawback often encountered with other inorganic and metallic NPs [40].

The concept of preparing CaP-NPs for the encapsulation of RNA or DNA molecules, as opposed to surface decoration or adsorption where the therapeutic agent is not protected from the biological environment, is not new per se [41]. This strategy requires the presence of a capping agent to prevent the formation of large polydisperse and polymorphous micro-sized particles [42], and a variety of capping agents mainly based on synthetic polymers such as polyethylene glycol [43], poly(methacrylic acid) [44] or polyethylenimine [45] have been already used to stabilize $\mathrm{CaP}$ particles for gene delivery. However, synthetic polymers such as polyethylenimine are cytotoxic and not suitable for the in vivo delivery of nucleic acids $[46,47]$. Therefore, the identification of alternative and more 'biofriendly' stabilizing agents is an effective need. In this study, we have modified the conventional synthesis of CaP-NPs by including $\mathrm{Na}_{3} \mathrm{Cit}$ in the synthesis process providing: improvement in the control of $\mathrm{CaP}$ growth tailoring the final dimensions, enhancement of colloidal stability and negative surface charge. In addition, and in contrast to previous synthetic polymers, we employed citrate, which is a fully biocompatible organic molecule present in several biological environments such as the bone apatite surface [48]. Finally, by applying a final step of dialysis, we drastically reduced the mean size of CaPNPs and increased their stability. In the last years, other authors employed citrate as stabilizing agent to prepare effective CaP-NPs as nonviral vectors for the delivery of nucleic acids [49-51]. However, here, differently from the previous works, miRNA was included during the synthesis of CaP-NP assisted by citrate, with the aim to encapsulate the active agent into the NPs as opposed to surface decoration for the reasons described above.

We recently introduced the concept that excitable cells are prone to (electro)toxicity. In fact, by measuring passive and active electrophysiologic properties of cardiomyocytes subjected to charged synthetic NPs, we found that polarized cells have a selective compatibility for negatively charged NPs [35,52]. In agreement with these results, the negatively charged CaP-NPs generated in this study did not affect any of the functional parameters we measured in cardiac cells. In particular, we did not observe any changes in passive membrane properties, known to be a signature of arrhythmogenesis [52]. The relevance of these results points to a 
promising employment of CaP-NPs for cardiac-related applications in vivo.

The functionalization of CaP-NPs with a negatively charged surface is beneficial also for crossing the lipid bilayer of the cell membrane. Our results showed that internalization of CaP-NPs occurs via clathrinmediated active endocytosis, which is in line with our previous study [35]. However, in a recent study it was also shown that $\mathrm{CaP}$ internalization in Hela and COS7 cells follows the caveolae-mediated path [53]. While this process is indeed effective in those cells [53], the caveolae-mediated internalization is most likely not occurring in excitable cells such as cardiomyocytes and HL-1 where on the other hand caveolae and lipid-rafts constitute well-organized microdomains deputed for the thorough regulation of cardiac ion channel function [54]. This is in line with our data showing that administration of CaP-NPs to cardiac cells does not induce any alteration in cell membrane capacitance (Supplementary Figure 4C), an index of absence of pinocytosis or caveosome endocytosis of lipid rafts [55].

Nowadays, a great effort is made toward the identification of nanoformulations capable of specific delivery of small therapeutic agents (i.e., nucleic acids or peptides) to tissues and cells [56]. To meet this demand, we have used an innovative approach for the generation of CaP-NPs, which can easily and cost-effectively bind miRNAs, small nucleic acids with enormous therapeutic potentials. In particular, we showed that CaP-NP-miRs are efficient for in vitro and in vivo miRNA delivery and able to target polarized tissues, such as the heart, although further improvements are still required to overcome limitations associated with cell-type specific targeting. In addition, the approach of encapsulating miRNAs into CaP-NPs bypasses potential problems occurring with the majority of current miRNA-delivery systems. In fact, in contrast to surface decoration or adsorption approaches, this approach increases the stability and functionality of miRNAs.

\section{Conclusion}

In summary, our study provides the proof of concept for an innovative, safe and efficient $\mathrm{CaP}$ based drugdelivery system in which the homogeneity of the nanocomplex can be controlled by adding citrate during the crystallization process. The resulting CaP-NPs were biocompatible with the viability and electrophysiology of a cardiac cell line and primary cardiomyocytes. In addition, CaP-NPs were demonstrated to carry and efficiently release miRNAs both in vitro and in vivo. All together, we envisage that the current study will open up new avenues for the potential application of CaP-NPs in the context of cardiac nanomedicine.

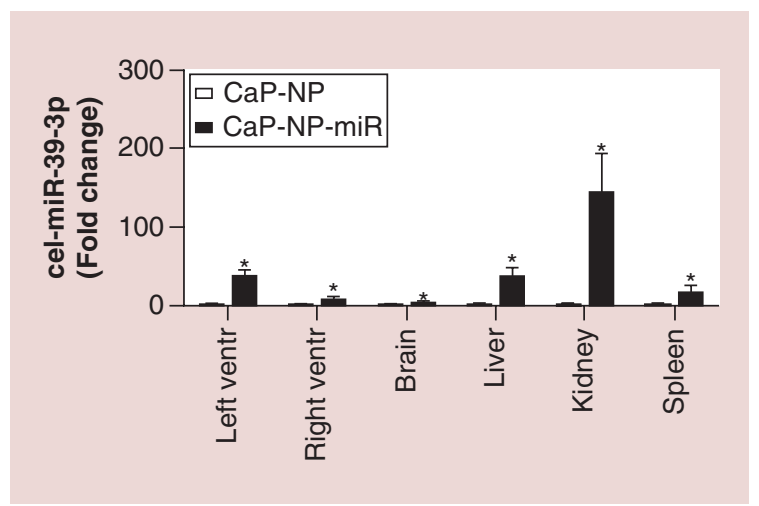

Figure 7. In vivo administration of CaP-NP-miRs. qRT-PCR performed on total RNA from various organs following 3 days of retro-orbital injection of CaP-NPmiRs carrying cel-miR-39-3p.

\section{Future perspective}

In this study we developed bioinspired and negatively surface charged NPs, which are able to encapsulate and carry miRNAs into cardiac cells both in vitro and in vivo. In the emerging field of nanomedicine, controlling the negative charge of the nanocarriers in terms of negative surface potential can be beneficial in facilitating the targeting of hyperpolarized and excitable organs. Further prospective studies, together with a long-term in vivo toxicity evaluation and comparison with other delivery systems, will provide evidence-based data to support the use of this nanoapproach for the treatment of CVD. Additionally, key investigations in support of effective human translatability and personalized medicine applications would require experimentations in cultured induced pluripotent stem cells derived cardiomyocytes from cardiac pathologies. This will contribute with better understanding of doses, toxicity and the beneficial miRNA effect together with the possibility to carry other drugs, peptides or siRNAs to the diseased heart. Altogether, this will open up the potential use of bioinspired and surface charged NPs for future therapeutic approaches.

\section{Supplementary data}

To view the supplementary data that accompany this paper please visit the journal website at: http://www.futuremedicine.com/doi/full/10.2217/nnm.16.26

\section{Acknowledgements}

HL-1 cells used in this study were kindly provided by Dr W Claycomb.

\section{Financial \& competing interests disclosure}

This work was supported by the Flagship project NanomaxmiRnano National Research Council grant to D Catalucci and A Tampieri, and a Young investigator grant from the Italian Ministry of Health (GR-2009-1530528) to M Miragoli. The authors have no other relevant affiliations or financial involve- 
ment with any organization or entity with a financial interest in or financial conflict with the subject matter or materials discussed in the manuscript apart from those disclosed.

No writing assistance was utilized in the production of this manuscript.

Ethical conduct of research

The authors state that they have obtained appropriate institutional review board approval or have followed the principles outlined in the Declaration of Helsinki for all animal experimental investigations.

\section{Open access}

This work is licensed under the Attribution-NonCommercialNoDerivatives 4.0 Unported License. To view a copy of this license, visit http://creativecommons.org/licenses/by-nc-nd/4.0/

\section{Executive summary}

\section{Objective}

- To develop biocompatible and bioresorbable negatively charged calcium-phosphate nanoparticles (CaP-NPs) as an innovative therapeutic system for the delivery of bioactive molecules to the heart.

\section{Experimental setup}

- CaP-NPs were synthetized via a straightforward one-pot biomineralization-inspired protocol employing citrate as a stabilizing agent and regulator of crystal growth.

- CaP-NPs were administered to cardiac cells in vitro and the effects of treatments were assessed.

- CaP-NPs were delivered in vivo.

Results

- CaP-NPs efficiently internalized into cardiomyocytes.

- CaP-NPs do not promote cell toxicity nor interfere with any functional properties of cardiomyocytes.

- CaP-NPs successfully encapsulated synthetic microRNAs, which were efficiently delivered into cardiac tissue in vitro and in vivo.

\section{Conclusion}

- CaP-NPs are a safe and efficient drug-delivery system for potential therapeutic treatments of polarized cells such as cardiomyocytes.

\section{References}

1 WHO. Cardiovascular diseases. www.who.int/cardiovascular_diseases/en/

2 Mosterd A, Hoes AW. Clinical epidemiology of heart failure. Heart 93(9), 1137-1146 (2007).

3 Olson EN. MicroRNAs as therapeutic targets and biomarkers of cardiovascular disease. Sci. Transl. Med. 6(239), 239ps233 (2014).

4 Romaine SP, Tomaszewski M, Condorelli G, Samani NJ. MicroRNAs in cardiovascular disease: an introduction for clinicians. Heart 101(12), 921-928 (2015).

5 Poller W, Hajjar R, Schultheiss HP, Fechner H. Cardiactargeted delivery of regulatory RNA molecules and genes for the treatment of heart failure. Cardiovasc. Res. 86(3), 353-364 (2010).

6 Eulalio A, Mano M, Dal Ferro M et al. Functional screening identifies miRNAs inducing cardiac regeneration. Nature 492(7429), 376-381 (2012).

7 Quattrocelli M, Crippa S, Montecchiani C et al. Long-term miR-669a therapy alleviates chronic dilated cardiomyopathy in dystrophic mice. J. Am. Heart Assoc. 2(4), e000284 (2013).

8 Fitzgerald KT, Holladay CA, Mccarthy C, Power KA, Pandit A, Gallagher WM. Standardization of models and methods used to assess nanoparticles in cardiovascular applications. Small 7(6), 705-717 (2011).

9 Matoba T, Egashira K. Nanoparticle-mediated drug delivery system for cardiovascular disease. Int. Heart J. 55(4), 281-286 (2014).
10 Suarez S, Almutairi A, Christman KL. Micro- and nanoparticles for treating cardiovascular disease. Biomater. Sci. 3(4), 564-580 (2015).

11 Chang MY, Yang YJ, Chang CH et al. Functionalized nanoparticles provide early cardioprotection after acute myocardial infarction. J. Control. Release 170(2), 287-294 (2013).

12 Gray WD, Che P, Brown M, Ning X, Murthy N, Davis ME. $\mathrm{N}$-acetylglucosamine conjugated to nanoparticles enhances myocyte uptake and improves delivery of a small molecule p38 inhibitor for post-infarct healing. J. Cardiovasc. Transl. Res. 4(5), 631-643 (2011).

13 Verma DD, Hartner WC, Levchenko TS, Bernstein EA, Torchilin VP. ATP-loaded liposomes effectively protect the myocardium in rabbits with an acute experimental myocardial infarction. Pharm. Res. 22(12), 2115-2120 (2005).

14 Canyon SJ, Dobson GP. Protection against ventricular arrhythmias and cardiac death using adenosine and lidocaine during regional ischemia in the in vivo rat. Am. J. Physiol. Heart C 287(3), H1286-H1295 (2004).

15 Liu M, Li M, Wang G et al. Heart-targeted nanoscale drug delivery systems. J. Biomed. Nanotechnol. 10(9), 2038-2062 (2014).

16 Thakor AS, Gambhir SS. Nanooncology: the future of cancer diagnosis and therapy. CA Cancer J. Clin. 63(6), 395-418 (2013).

17 Eloy JO, Claro De Souza M, Petrilli R, Barcellos JP, Lee RJ, Marchetti JM. Liposomes as carriers of hydrophilic 
small molecule drugs: strategies to enhance encapsulation and delivery. Colloids Surf. B. Biointerfaces 123, 345-363 (2014).

18 Kobayashi K, Wei JJ, Iida R, Ijiro K, Niikura K. Surface engineering of nanoparticles for therapeutic applications. Polym. J. 46(8), 460-468 (2014).

19 Miragoli M, Novak P, Ruenraroengsak P et al. Functional interaction between charged nanoparticles and cardiac tissue: a new paradigm for cardiac arrhythmia? Nanomedicine (Lond.) 8(5), 725-737 (2013).

20 Claycomb WC, Lanson NA Jr, Stallworth BS et al. HL-1 cells: a cardiac muscle cell line that contracts and retains phenotypic characteristics of the adult cardiomyocyte. Proc. Natl Acad. Sci. USA 95(6), 2979-2984 (1998).

21 Catalucci D, Zhang DH, Desantiago J et al. Akt regulates L-type $\mathrm{Ca}^{2+}$ channel activity by modulating Cavalpha1 protein stability. J. Cell Biol. 184(6), 923-933 (2009).

22 Castaldi A, Zaglia T, Di Mauro V et al. MicroRNA-133 modulates the beta1-adrenergic receptor transduction cascade. Circ. Res. 115(2), 273-283 (2014).

23 Bang C, Batkai S, Dangwal S et al. Cardiac fibroblastderived microRNA passenger strand-enriched exosomes mediate cardiomyocyte hypertrophy. J. Clin. Invest. 124(5), 2136-2146 (2014).

24 Beniash E. Biominerals-hierarchical nanocomposites: the example of bone. Wiley Interdiscip. Rev. Nanomed. Nanobiotechnol. 3(1), 47-69 (2011).

25 Morgan TT, Muddana HS, Altinoglu EI et al. Encapsulation of organic molecules in calcium phosphate nanocomposite particles for intracellular imaging and drug delivery. Nano Lett. 8(12), 4108-4115 (2008).

26 Iafisco M, Palazzo B, Martra G et al. Nanocrystalline carbonate-apatites: role of $\mathrm{Ca} / \mathrm{P}$ ratio on the upload and release of anticancer platinum bisphosphonates. Nanoscale 4(1), 206-217 (2012).

27 Iafisco M, Delgado-Lopez JM, Varoni EM et al. Cell surface receptor targeted biomimetic apatite nanocrystals for cancer therapy. Small 9(22), 3834-3844 (2013).

28 Rodriguez-Ruiz I, Delgado-Lopez JM, Duran-Olivencia MA et al. $\mathrm{pH}$-responsive delivery of doxorubicin from citrate-apatite nanocrystals with tailored carbonate content. Langmuir 29(26), 8213-8221 (2013).

29 Li D, He J, Huang X et al. Intracellular $\mathrm{pH}$-responsive mesoporous hydroxyapatite nanoparticles for targeted release of anticancer drug. RSC Adv. 5(39), 30920-30928 (2015).

30 Lacerda L, Bianco A, Prato M, Kostarelos K. Carbon nanotubes as nanomedicines: from toxicology to pharmacology. Adv. Drug Deliv. Rev. 58(14), 1460-1470 (2006).

31 Delgado-López JM, Frison R, Cervellino A, Gómez-Morales J, Guagliardi A, Masciocchi N. Crystal size, morphology, and growth mechanism in bio-inspired apatite nanocrystals. Adv. Funct. Mater. 24(8), 1090-1099 (2014).

32 Davies E, Muller KH, Wong WC et al. Citrate bridges between mineral platelets in bone. Proc. Natl Acad. Sci. USA 111(14), E1354-E1363 (2014).
33 Delgado-Lopez JM, Iafisco M, Rodriguez I, Tampieri A, Prat M, Gomez-Morales J. Crystallization of bioinspired citratefunctionalized nanoapatite with tailored carbonate content. Acta Biomater. 8(9), 3491-3499 (2012).

34 Termine JD, Posner AS. Infra-red determinaion of the percentage of crystallinity in apatitic calcium phosphates. Nature 211(5046), 268-270 (1966).

35 Novak P, Shevchuk A, Ruenraroengsak P et al. Imaging single nanoparticle interactions with human lung cells using fast ion conductance microscopy. Nano Lett. 14(3), 1202-1207 (2014).

36 Spindler AJ, Noble SJ, Noble D. Comparison of step and ramp voltage clamp on background currents in guinea-pig ventricular cells. Exp. Physiol. 84(5), 865-879 (1999).

37 Bers DM. Cardiac excitation-contraction coupling. Nature 415(6868), 198-205 (2002).

38 Doane TL, Burda C. The unique role of nanoparticles in nanomedicine: imaging, drug delivery and therapy. Chem. Soc. Rev. 41(7), 2885-2911 (2012).

39 Roveri N, Palazzo B, Iafisco M. The role of biomimetism in developing nanostructured inorganic matrices for drug delivery. Expert Opin. Drug Deliv. 5(8), 861-877 (2008).

40 Singh N, Jenkins GJ, Asadi R, Doak SH. Potential toxicity of superparamagnetic iron oxide nanoparticles (SPION). Nano Rev. 1, doi:10.3402/nano.v1i0.5358 (2010).

41 Jung H, Kim SA, Yang YG, Yoo H, Lim SJ, Mok H. Long chain microRNA conjugates in calcium phosphate nanoparticles for efficient formulation and delivery. Arch. Pharm. Res. 38(5), 705-715 (2015).

42 Xie Y, Chen Y, Sun M, Ping Q. A mini review of biodegradable calcium phosphate nanoparticles for gene delivery. Curr. Pharm. Biotechnol. 14(10), 918-925 (2013).

43 Kakizawa Y, Kataoka K. Block copolymer self-assembly into monodispersive nanoparticles with hybrid core of antisense DNA and calcium phosphate. Langmuir 18(12), 4539-4543 (2002).

44 Kakizawa Y, Furukawa S, Ishii A, Kataoka K. Organicinorganic hybrid-nanocarrier of siRNA constructing through the self-assembly of calcium phosphate and PEG-based block aniomer. J. Control. Release 111(3), 368-370 (2006).

45 Devarasu T, Saad R, Ouadi A et al. Potent calcium phosphate nanoparticle surface coating for in vitro and in vivo siRNA delivery: a step toward multifunctional nanovectors. J. Mater. Chem. B 1(36), 4692-4700 (2013).

46 Vilar G, Tulla-Puche J, Albericio F. Polymers and drug delivery systems. Curr. Drug Deliv. 9(4), 367-394 (2012).

47 Moghimi SM, Symonds P, Murray JC, Hunter AC, Debska G, Szewczyk A. A two-stage poly(ethylenimine)-mediated cytotoxicity: implications for gene transfer/therapy. Mol. Ther. 11(6), 990-995 (2005).

48 Hu YY, Rawal A, Schmidt-Rohr K. Strongly bound citrate stabilizes the apatite nanocrystals in bone. Proc. Natl Acad. Sci. USA 107(52), 22425-22429 (2010).

49 Banik M, Basu T. Calcium phosphate nanoparticles: a study of their synthesis, characterization and mode of interaction with salmon testis DNA. Dalton Trans. 43(8), 3244-3259 (2014). 
50 Li J, Chen YC, Tseng YC, Mozumdar S, Huang L. Biodegradable calcium phosphate nanoparticle with lipid coating for systemic siRNA delivery. J. Control. Release 142(3), 416-421 (2010)

51 Banik M, Mukherjee R, Patra M et al. Spectrofluorimetric study on in vitro interaction between calcium phosphate nanoparticle and salmon testis DNA. J. Nanopart. Res. 16(1), 1-11 (2013).

52 Savi M, Rossi S, Bocchi L et al. Titanium dioxide nanoparticles promote arrhythmias via a direct interaction with rat cardiac tissue. Part. Fibre Toxicol. 11, 63 (2014).
53 Olton DY, Close JM, Sfeir CS, Kumta PN. Intracellular trafficking pathways involved in the gene transfer of nanostructured calcium phosphate-DNA particles. Biomaterials 32(30), 7662-7670 (2011).

54 Maguy A, Hebert TE, Nattel S. Involvement of lipid rafts and caveolae in cardiac ion channel function. Cardiovasc. Res. 69(4), 798-807 (2006).

55 Nichols B. Caveosomes and endocytosis of lipid rafts. J. Cell Sci. 116(Pt 23), 4707-4714 (2003).

56 Dizaj SM, Jafari S, Khosroushahi AY. A sight on the current nanoparticle-based gene delivery vectors. Nanoscale Res. Lett. 9(1), $252(2014)$ 